\title{
Tie2-dependent deletion of $\alpha 6$ integrin subunit in mice reduces tumor growth and angiogenesis
}

\author{
CLAIRE BOUVARD ${ }^{1,2,3,7}$, ZACHARIE SEGAOULA ${ }^{1,2}$, ADÈLE DE ARCANGELIS $^{4}$, \\ ISABELLE GALY-FAUROUX ${ }^{2,5}$, LAETITIA MAUGE ${ }^{2,5,6}$, ANNE-MARIE FISCHER ${ }^{2,5,6}$, \\ ELISABETH GEORGES-LABOUESSE ${ }^{4}$ and DOMINIQUE HELLEY ${ }^{2,5,6}$
}

\author{
${ }^{1}$ INSERM UMR-S765; ${ }^{2}$ University Paris Descartes, Sorbonne Paris Cité; ${ }^{3}$ University Paris Diderot, \\ Sorbonne Paris Cité, Paris; ${ }^{4}$ Institute of Genetics, Cellular and Molecular Biology, INSERM U964, \\ CNRS UMR 7104, University of Strasbourg, Illkirch; ${ }^{5}$ INSERM UMR-S970 PARCC; \\ ${ }^{6}$ AP-HP, European Hospital Georges Pompidou, Paris, France
}

Received June 7, 2014; Accepted July 17, 2014

DOI: 10.3892/ijo.2014.2631

\begin{abstract}
The $\alpha 6$ integrin subunit $(\alpha 6)$ has been implicated in cancer cell migration and in the progression of several malignancies, but its role in tumor angiogenesis is unclear. In mice, anti- $\alpha 6$ blocking antibodies reduce tumor angiogenesis, whereas Tie1-dependent $\alpha 6$ gene deletion enhances neovessel formation in melanoma and lung carcinoma. To clarify the discrepancy in these results we used the cre-lox system to generate a mouse line, $\alpha 6 \mathrm{fl} / \mathrm{fl}-\mathrm{Tie} 2 \mathrm{Cre}^{+}$, with $\alpha 6$ gene deletion specifically in Tie2-lineage cells: endothelial cells, pericytes, subsets of hematopoietic stem cells, and Tie2-expressing monocytes/macrophages (TEMs), known for their proangiogenic properties. Loss of $\alpha 6$ expression in $\alpha 6 \mathrm{fl} / \mathrm{fl}-\mathrm{Tie} 2 \mathrm{Cre}^{+}$ mice reduced tumor growth in a murine B16F10 melanoma model. Immunohistological analysis of the tumors showed that Tie2-dependent $\alpha 6$ gene deletion was associated with reduced tumor vascularization and with reduced infiltration of proangiogenic Tie2-expressing macrophages. These findings demonstrate that $\alpha 6$ integrin subunit plays a major role in tumor angiogenesis and TEM infiltration. Targeting $\alpha 6$ could be used as a strategy to reduce tumor growth.
\end{abstract}

\section{Introduction}

The extracellular matrix and integrins, their cellular receptors, play key roles in tumor progression and tumor angiogenesis,

Correspondence to: Dr Claire Bouvard, INSERM UMR-S765, Faculté des Sciences Pharmaceutiques et Biologiques, 4 Avenue de l'Observatoire, F-75006 Paris, France

E-mail: bouvard.claire@gmail.com

Present addresses: ${ }^{7}$ California Institute for Biomedical Research, La Jolla, CA, USA; ${ }^{10}$ INSERM UMR-S970, Paris, France

Key words: $\alpha 6$, tumor angiogenesis, integrins, Tie2-expressing macrophages, genetic mouse model and blocking antibodies against $\alpha v \beta 3, \alpha v \beta 5$ and $\alpha 5 \beta 1$ are currently under development as potential cancer therapies $(1,2)$. The $\alpha 6$ integrin subunit is expressed by endothelial cells, platelets, monocytes/macrophages, neutrophils, epithelial cells and Schwann cells (3-6). It can associate with $\beta 1$ or $\beta 4$ subunits to form receptors for laminins, which are major components of the extracellular matrix and endothelial basement membrane (7). A role of $\alpha 6$ integrin subunit has been demonstrated in the progression of several malignancies such as breast cancer, prostate cancer, glioblastoma and pancreatic cancer. $\alpha 6$ integrin overexpression or de novo expression by tumor cells (depending on the type of cancer) is associated with a poor prognosis. Indeed, $\alpha 6$ expression increases cell motility and adhesion, which confers invasive properties to tumor cells (8-12). $\alpha 6$ is also strongly expressed on endothelial cells, and its expression is enhanced by proangiogenic growth factors such as VEGF and FGF2 (13-17). We have previously shown that $\alpha 6$ is involved in endothelial cell adhesion, migration, pseudotube formation and post-ischemic vascular repair $(13,14,18,19)$. Moreover, $\alpha 6$ binds laminin 411 (laminin 8) and laminin 511 (laminin 10) (7), expression of which is upregulated in the basement membrane of tumor blood vessels in invasive brain (20) and breast (21) carcinomas. $\alpha 6$ targeting could potentially have therapeutic benefits by disrupting tumor angiogenesis and growth, but the role of $\alpha 6$ in tumor angiogenesis is controversial. In a breast carcinoma xenograft model (MDA-MB-231), Lee et al (16) found that an anti- $\alpha 6$ blocking antibody reduced tumor volume, tumor weight and blood vessel abundance. However, these effects might have resulted from either an antitumoral effect or anti-angiogenic activity or both effects. To resolve this issue, Primo et al (17) used Rip-Tag2 mice, which spontaneously develop pancreatic tumors that do not express $\alpha 6$. They found that $\alpha 6$ expression on tumor blood vessels was increased during the angiogenic stage and that administration of an anti- $\alpha 6$ blocking antibody reduced tumor vascularization. However, other authors obtained opposite results with a genetically manipulated mouse model. Germain et al (22) generated mice in which $\alpha 6$ gene deletion was restricted to endothelial cells, by using 
the cre-lox system under the control of the Tiel promoter. However, Tie1-dependent $\alpha 6$ deletion was counterbalanced by VEGFR2 overexpression, resulting in enhanced tumor growth and angiogenesis. Further investigation was thus required to clarify the role for $\alpha 6$ in tumor angiogenesis.

To understand the discrepancy in the results reported in the different studies cited above we generated a mouse model in which the gene coding for $\alpha 6$ was deleted by using the cre-lox system under the control of the Tie2 promoter, leading to $\alpha 6$ gene deletion only in Tie2-lineage cells (endothelial cells, subsets of hematopoietic stem cells, pericytes and monocytes/macrophages). We investigated the effect of this Tie2-dependent $\alpha 6$ gene deletion on B16F10 melanoma growth, tumor angiogenesis, macrophage infiltration and pericyte coverage by comparing $\alpha 6 \mathrm{fl} / \mathrm{fl}-\mathrm{Tie} 2 \mathrm{Cre}^{+}$and $\alpha 6 f l / f l-T i e 2 \mathrm{Cre}^{-}$mice.

\section{Materials and methods}

Animals. We generated $\alpha 6$ floxed mice [Itga $6^{\operatorname{tm} 2 \mathrm{Eg} 1}$, MGI:4439081] as previously described and bred them with mice expressing Cre recombinase under the control of the Tie2 promoter [B6.Cg-Tg(Tek-cre)12Flv/J], purchased from Jackson Laboratory (Bar Harbor, ME, USA), in order to generate $\alpha 6 \mathrm{fl} /$ fl-Tie2Cre ${ }^{+}$and $\alpha 6$ fl/fl-Tie2Cre ${ }^{-}$mice (on a C57BL/6 background) (19). All the protocols were approved by the Regional Ethics Committee on Animal Experimentation (protocol CEEA34.CB.041.11) and all the experiments complied with European Parliament Directive 2010/63/EU. The adequacy of anesthesia was confirmed by the lack of the tail pinch response.

Tumor growth assay. One million B16F10 melanoma cells (syngeneic to C57BL/6 mice) were suspended in $100 \mu \mathrm{l}$ of PBS and injected subcutaneously in the right flank of 8-week-old $\alpha 6 f l / f l-T i e 2 \mathrm{Cre}^{+}$and $\alpha 6 \mathrm{fl} / \mathrm{fl}-\mathrm{Tie} 2 \mathrm{Cre}^{-}$male mice. Tumor growth was quantified by Vernier caliper measurements every 2 or 3 days. Tumor volume was calculated as $0.5 \mathrm{x}$ length $\mathrm{x}$ width ${ }^{2}$. At the end of the experiment the mice were anesthetized with a single intraperitoneal injection of ketamine $(80 \mathrm{mg} / \mathrm{kg})$ and xylazine $(16 \mathrm{mg} / \mathrm{kg})$, then sacrificed by cervical dislocation. Tumors were harvested, weighed and frozen in isopentane solution cooled in liquid nitrogen before being stored at $-80^{\circ} \mathrm{C}$ until immunohistological analysis. Two different independent experiments were performed. For one experiment all the tumors were harvested at Day 12 ( $n=7$ to 9 mice/genotype), and for another experiment the tumors were harvested at different time points in order to analyze size-matched tumors ( $n=10$ per genotype).

Immunohistological tumor analysis. For all immunofluorescence experiments, frozen $10-\mu$ m-thick sections of tumors from $\alpha 6$ fl/fl-Tie2Cre ${ }^{+}$and $\alpha 6 f l / f l-T i e 2 \mathrm{Cre}^{-}$mice were fixed in ice-cold acetone for $10 \mathrm{~min}$, stained as described below and examined by an observer in a blinded manner using a confocal microscope (TCS SP2, Leica, Wetzlar, Germany).

Study of $\alpha 6$ integrin subunit co-expression with laminin chains $\alpha 4$ and $\alpha 5$. Tumor sections were incubated for $1 \mathrm{~h}$ with the following primary antibodies: rabbit anti-mouse laminin $\alpha 4$ (23), rabbit anti-mouse laminin $\alpha 5$ (24) (both generous gifts from Sorokin LM, University of Muenster, Germany) or rat anti-human $\alpha 6$ (clone GoH3, BD Biosciences, Franklin Lakes, $\mathrm{NJ}$, USA), then further incubated for $1 \mathrm{~h}$ with the following secondary antibodies: goat anti-rabbit Alexa555 (Invitrogen, Carlsbad, CA, USA) or goat anti-rat FITC (Abcam, Cambridge, MA, USA). Nuclei were stained with TOPRO3-Iodide (Thermo Fischer Scientific, Waltham, MA, USA).

Analysis of tumor vascularization. Tumor sections were incubated for $1 \mathrm{~h}$ with a rat anti-mouse CD31 monoclonal antibody (clone MEC 13.3, BD Biosciences), then with a goat anti-rat secondary antibody coupled to FITC (Abcam). Ten fields were examined per section. The vessel surface area, the number of vessels and vessel diameter were quantified with Histolab ${ }^{\mathrm{TM}}$ software (Microvision Instruments, Evry, France). Results were expressed as the vessel surface area (\%), the number of vessels $/ \mathrm{mm}^{2}$ and mean vessel diameter.

Quantification of Tie2-expressing macrophages. Tumor sections were sequentially incubated with the following antibodies: rat anti-mouse F4/80 (Abd Serotec, Düsseldorf, Germany), goat anti-rat FITC, biotinylated rat anti-mouse Tie2 (eBiosciences, San Diego, CA, USA) and streptavidin-Alexa 555 (Invitrogen). Ten fields were examined per section and the numbers of Tie2-expressing macrophages (TEMs) $\left(\mathrm{F} 4 / 80^{+} \mathrm{Tie}^{+}\right)$and total macrophages $\left(\mathrm{F} 4 / 80^{+}\right)$were determined with Image $\mathrm{J}$ and Histolab $^{\text {TM }}$ (Microvision) software. Results were expressed as the number of TEMs and total macrophages $/ \mathrm{mm}^{2}$ and as the percentage of TEMs in the total macrophage population.

Analysis of pericyte coverage. Tumor sections were incubated with the following primary antibodies: biotinylated mouse anti-smooth muscle actin ( $\alpha$ SMA) (Clone 1A4, Thermo Fischer Scientific), rat anti-mouse CD31 (clone mec13.3, BD Biosciences), and then with streptavidin Cy3 (Amersham, Little Chalfont, UK) and goat anti-rat Alexa 488 (Invitrogen). Ten fields were examined per section. The number of blood vessels positive for $\alpha \mathrm{SMA}$, and the surface areas stained for CD31 (endothelial cells) and $\alpha$ SMA (pericytes) were determined with Image $\mathbf{J}$ software. Results were expressed as a percentage of blood vessels positive for $\alpha$ SMA and as a ratio of $\alpha$ SMA/CD31 surface areas.

Blood sampling and analysis of monocyte $\alpha 6$ expression. Eight-week-old $\alpha 6 \mathrm{fl} / \mathrm{fl}-\mathrm{Tie} 2 \mathrm{Cre}^{+}$and $\alpha 6 \mathrm{fl} / \mathrm{fl}-\mathrm{Tie} 2 \mathrm{Cre}^{-}$mice were anesthetized with a single intraperitoneal injection of ketamine $(80 \mathrm{mg} / \mathrm{kg})$ and xylazine $(16 \mathrm{mg} / \mathrm{kg})$. Peripheral blood was collected by cardiac puncture and the mice were sacrificed by cervical dislocation. Peripheral blood samples were incubated with CD45-PerCP and CD49f-PE (clone GoH3) or isotypematched irrelevant antibodies (BD Biosciences). After a lysis step (FACS lysing solution, BD Biosciences), monocyte $\alpha 6$ expression was analyzed on a FACS Calibur flow cytometer using Cell Quest Pro software (BD Biosciences). A SSC/CD45PerCP dot plot was used for monocyte gating. Results were expressed as the percentage of monocytes positive or negative for $\alpha 6$ expression among the total monocyte population.

Statistical analysis. Results are expressed as means \pm SEM. Data were analyzed using ANOVA followed by Fisher's PLSD 

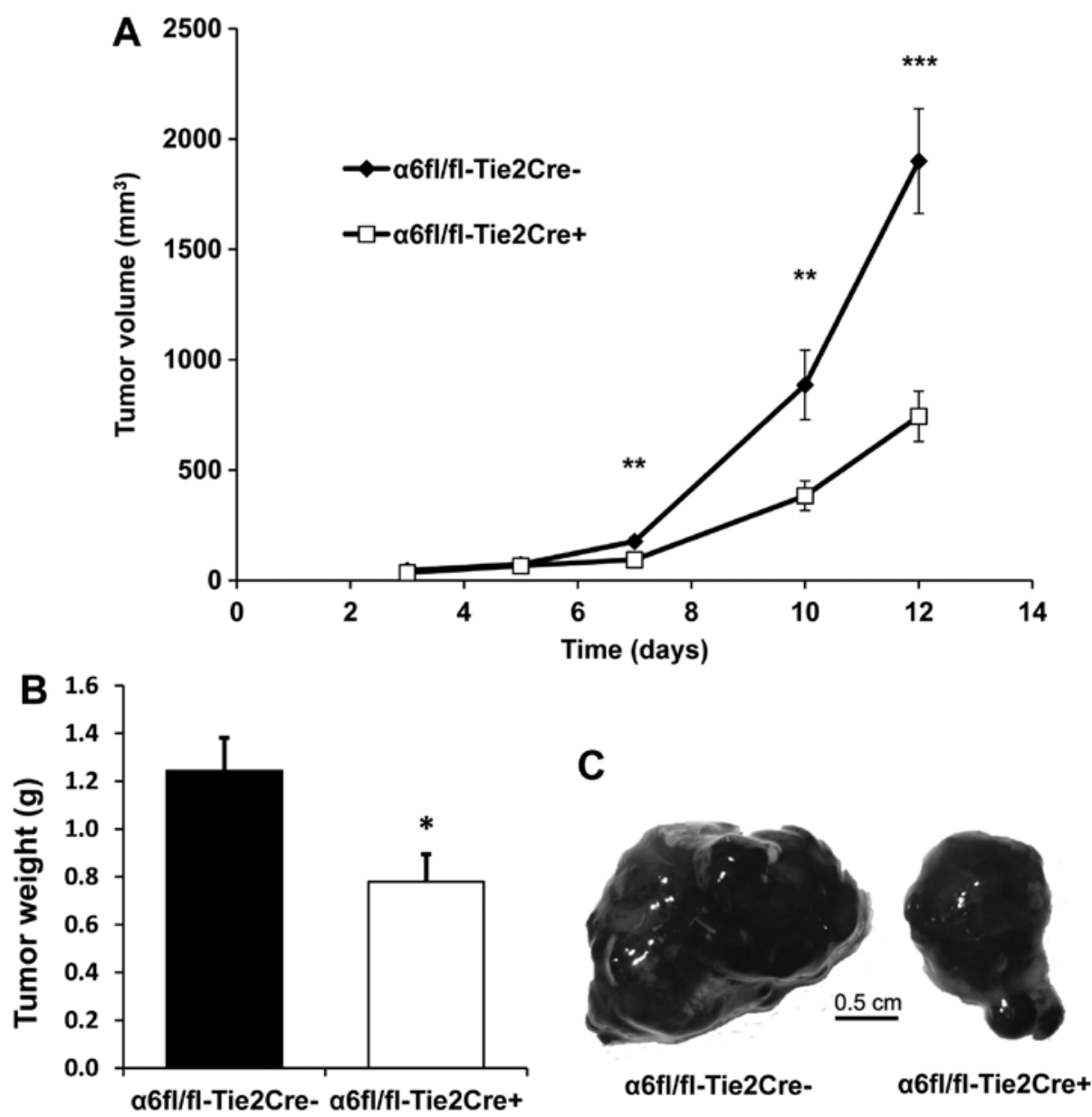

Figure 1. Tie2-dependent $\alpha 6$ deletion reduces tumor growth. Kinetics of tumor growth (A) assessed by Vernier caliper measurements in $\alpha 6 \mathrm{fl} / \mathrm{fl}-\mathrm{Tie} 2 \mathrm{Cre}-\mathrm{e}^{-}, \mathrm{n}=7$ ) and $\alpha 6 \mathrm{fl} / \mathrm{fl} 1-\mathrm{Tie}_{2} \mathrm{Cre}^{+}(\square, \mathrm{n}=9)$ mice. Tumor weight (B) and representative photomicrographs (C) of B16F10 tumors from $\alpha 6 \mathrm{fl} / \mathrm{fl}-\mathrm{Tie} 2 \mathrm{Cre}-(\mathbf{\square}, \mathrm{n}=7)$ and $\alpha 6 \mathrm{fl} / \mathrm{fl}-\mathrm{Tie}_{2} \mathrm{Cre}^{+}(\square, \mathrm{n}=9)$ mice 12 days after tumor implantation. Scale bar, $0.5 \mathrm{~cm}$. Data are means $\pm \mathrm{SEM} .{ }^{*} \mathrm{P}<0.05,{ }^{* *} \mathrm{P}<0.01$ and ${ }^{* * * *} \mathrm{P}<0.001$.

post hoc test implemented with StatView software (SAS, Cary, NC, USA). Significance was assumed at $\mathrm{P}<0.05$.

\section{Results}

Tie2-dependent deletion of $\alpha 6$ integrin subunit reduces tumor growth. The growth of subcutaneous B16F10 tumors was significantly reduced in $\alpha 6 f l / f l-T i e 2 \mathrm{Cre}^{+}$mice $(\mathrm{n}=9)$ compared to $\alpha 6 \mathrm{fl} / \mathrm{fl}$-Tie2Cre ${ }^{-}$mice $(\mathrm{n}=7)$ : tumor volume was reduced by $56 \%$ at Day $10(\mathrm{P}<0.01)$ and by $60 \%$ at Day $12(\mathrm{P}<0.001)$ (Fig. 1A), while tumor weight was reduced by $37 \%$ at Day 12 $(\mathrm{P}<0.05)$ (Fig. 1B).

Tie2-dependent deletion of $\alpha 6$ integrin subunit reduces tumor angiogenesis. Immunofluorescence experiments showed that $\alpha 6$ was expressed on tumor blood vessels from $\alpha 6 \mathrm{fl} / \mathrm{fl}-\mathrm{Tie} 2 \mathrm{Cre}$ mice and was associated with laminin $\alpha 4$ and $\alpha 5$ chains. Endothelial $\alpha 6$ deletion was complete in $\alpha 6 \mathrm{fl} / \mathrm{fl}-\mathrm{Tie} 2 \mathrm{Cre}^{+}$mice (Fig. 2).

For tumors harvested at Day 12, vessel density was reduced in tumors from $\alpha 6 \mathrm{fl} / \mathrm{fl}-\mathrm{Tie} 2 \mathrm{Cre}^{+}$mice $(\mathrm{n}=9)$ compared to $\alpha 6 \mathrm{fl} / \mathrm{fl}-\mathrm{Tie} 2 \mathrm{Cre}-$ mice $(\mathrm{n}=7)$ : both vessel number $/ \mathrm{mm}^{2}$ and vessel surface area were reduced by $58 \%(\mathrm{P}<0.001)$. The average diameter of tumor blood vessels was significantly larger in $\alpha 6 \mathrm{fl} / \mathrm{fl}-\mathrm{Tie} 2 \mathrm{Cre}^{+}$mice than in $\alpha 6 \mathrm{fl} / \mathrm{fl}-\mathrm{Tie} 2 \mathrm{Cre}^{-}$mice $(\mathrm{P}<0.05)$ (Fig. 3A and B).

To rule out an effect of tumor size on angiogenesis we also analyzed tumor vascularization in size-matched tumors from $\alpha 6 \mathrm{fl} / \mathrm{fl}-\mathrm{Tie} 2 \mathrm{Cre}^{+}$and $\alpha 6 \mathrm{fl} / \mathrm{fl}-\mathrm{Tie} 2 \mathrm{Cre}^{-}$mice, harvested at varying time points. Vessel density was reduced in tumors from $\alpha 6 \mathrm{fl} / \mathrm{fl}-\mathrm{Tie} 2 \mathrm{Cre}^{+}$mice $(\mathrm{n}=10)$ compared to $\alpha 6 \mathrm{fl} / \mathrm{fl}-\mathrm{Tie} 2 \mathrm{Cre}$ mice $(\mathrm{n}=10)$ : the number of vessels $/ \mathrm{mm}^{2}$ was reduced by $41 \%$ $(\mathrm{P}<0.001)$ and vessel surface area by $48 \%(\mathrm{P}<0.01)$ (Fig. $3 \mathrm{C})$.

Tie2-dependent deletion of $\alpha 6$ integrin subunit reduces infiltration by Tie2-expressing macrophages. For tumors harvested at Day 12, the number of TEMs per square millimeter was reduced by $55 \%$ in tumors from $\alpha 6 \mathrm{fl} / \mathrm{fl}-\mathrm{Tie} 2 \mathrm{Cre}^{+}$mice $(\mathrm{n}=9)$ compared to $\alpha 6 \mathrm{fl} / \mathrm{fl} \mathrm{l}-\mathrm{Tie} 2 \mathrm{Cre}^{-}$mice $(\mathrm{n}=7)(\mathrm{P}<0.05)$. Tie2dependent deletion of $\alpha 6$ also led to a $32 \%$ reduction in the percentage of TEMs among the total macrophage population $(\mathrm{P}<0.001)$. The total number of macrophages in tumors from $\alpha 6 \mathrm{fl} / \mathrm{fl}-\mathrm{Tie} 2 \mathrm{Cre}^{+}$mice was also reduced, but the difference with a6fl/fl-Tie2Cre- mice was not statistically significant (Fig. 4A and $\mathrm{B}$ ). The analysis of size-matched tumors ( $\mathrm{n}=10 \mathrm{mice} / \mathrm{geno}-$ type) led to the same results with no significant difference observed between size-matched tumors and tumors harvested at Day 12 (Fig. 4C). 
A

$\alpha 6 f \mathrm{fl} / \mathrm{fl}-\mathrm{Tie} 2 \mathrm{Cre}-\alpha 6 \mathrm{fl} / \mathrm{fl}-\mathrm{Tie} 2 \mathrm{Cre}+$
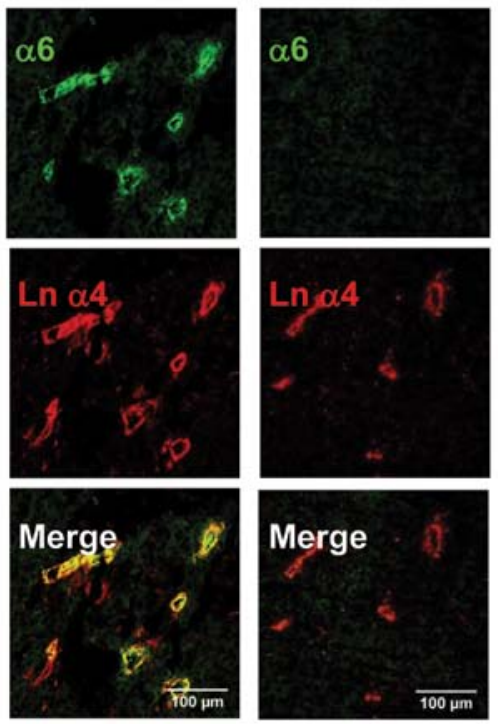

B

$\alpha 6 \mathrm{fl} / \mathrm{fl}-\mathrm{Tie} 2 \mathrm{Cre}-\alpha 6 \mathrm{fl} / \mathrm{fl}-\mathrm{Tie} 2 \mathrm{Cre}+$
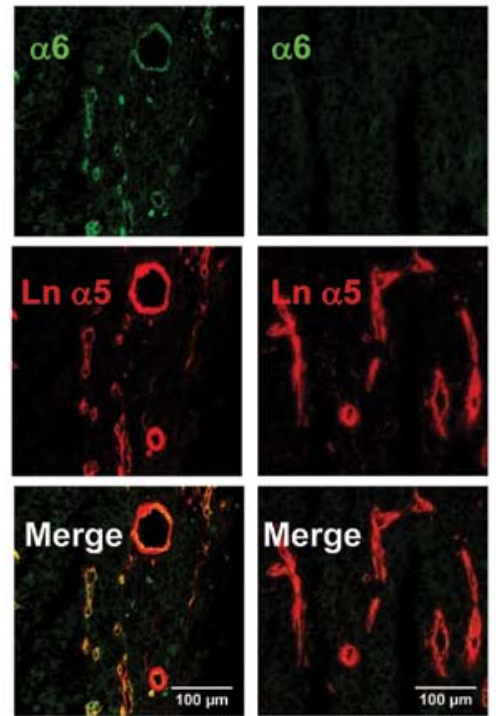

Figure 2. Laminin $\alpha 4$ and $\alpha 5$ chains colocalize with integrin $\alpha 6$. Representative photomicrographs of cryosections of B16F10 tumors from $\alpha 6$ fl/fl-Tie2Cre and $\alpha 6 \mathrm{fl} / \mathrm{fl}-\mathrm{Tie} 2 \mathrm{Cre}^{+}$mice. Integrin $\alpha 6$ was immunostained in green with antibody GoH3 and with a secondary antibody coupled to FITC. Laminin $\alpha 4$ (A) and $\alpha 5$ chains (B) were stained in red with rabbit antibodies and with a secondary antibody coupled to Alexa 555 . Scale bars, $100 \mu \mathrm{m}$.

A $\quad \alpha 6 f l / f l-T i e 2 C r e-$
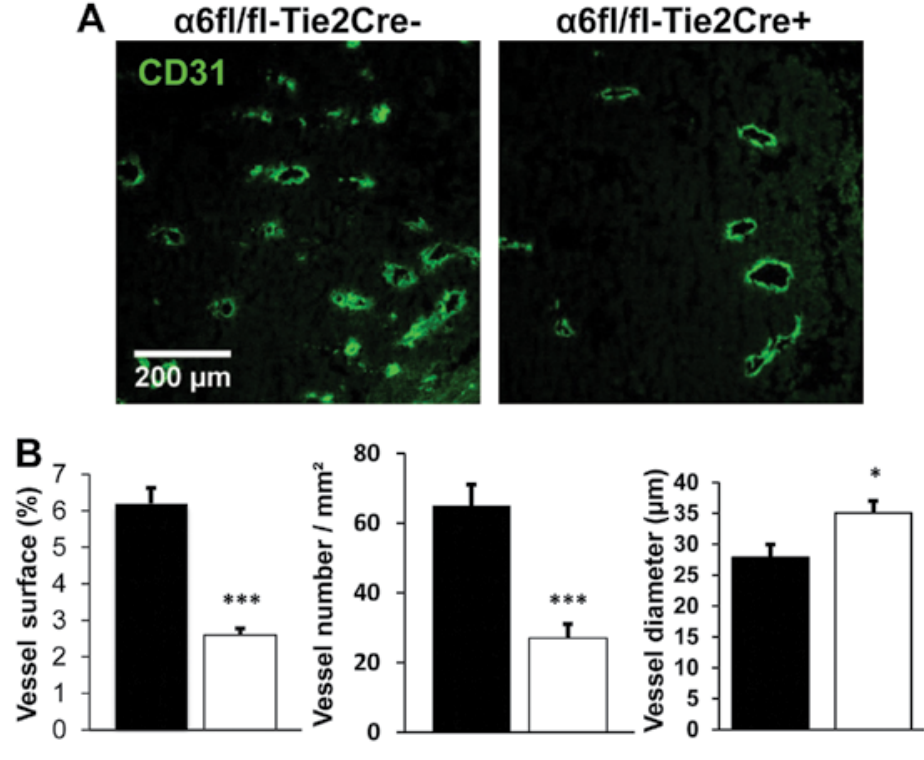

- a6fl/fl-Tie2Cre-

$\square$ a6fl/fl-Tie2Cre+
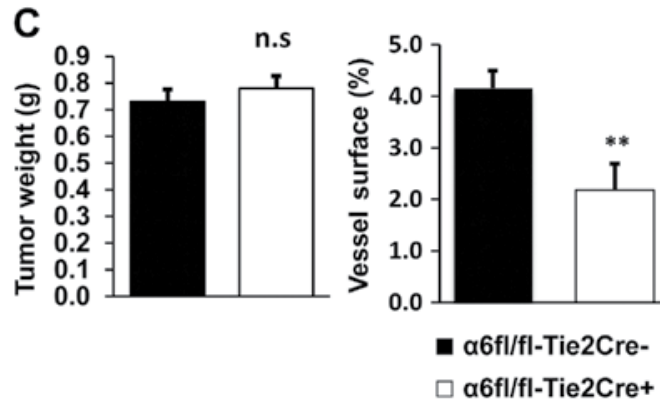

Figure 3. Tie2-dependent $\alpha 6$ deletion reduces tumor vascularization. Representative photomicrographs (A) and quantitative analysis of the vessel surface area (\%), the number of vessels $/ \mathrm{mm}^{2}$, and mean vessel diameter on cryosections of B16F10 tumors from $\alpha 6 \mathrm{fl} / \mathrm{fl}-\mathrm{Tie} 2 \mathrm{Cre}{ }^{-}(\boldsymbol{\square}, \mathrm{n}=7)$ and $\alpha 6 \mathrm{fl} / \mathrm{fl}-\mathrm{Tie} 2 \mathrm{Cre}{ }^{+}(\square, \mathrm{n}=9)$ mice, 12 days after tumor implantation (B) or when tumors have identical size in the 2 groups ( $=10$ in each group) (C). Vessels were stained green with an anti-CD31 antibody. Scale bar, $200 \mu \mathrm{m}$. Data are means \pm SEM. ${ }^{*} \mathrm{P}<0.05$ and ${ }^{* *} \mathrm{P}<0.01$. 
A
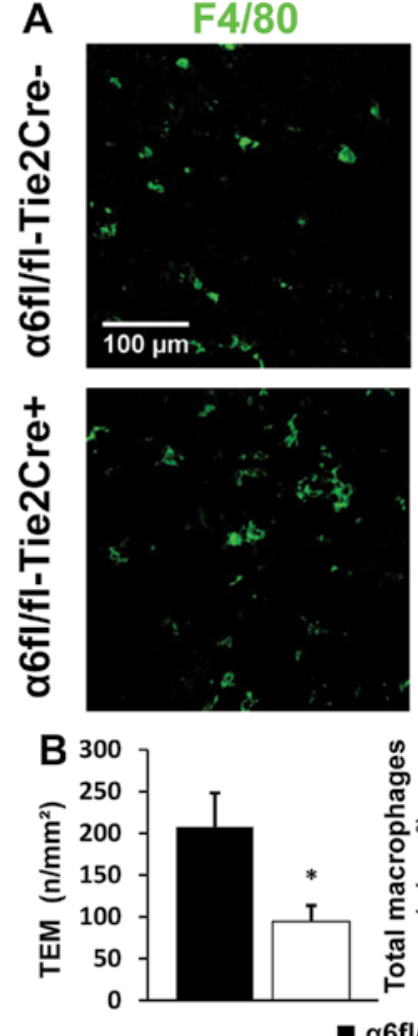

Tie2
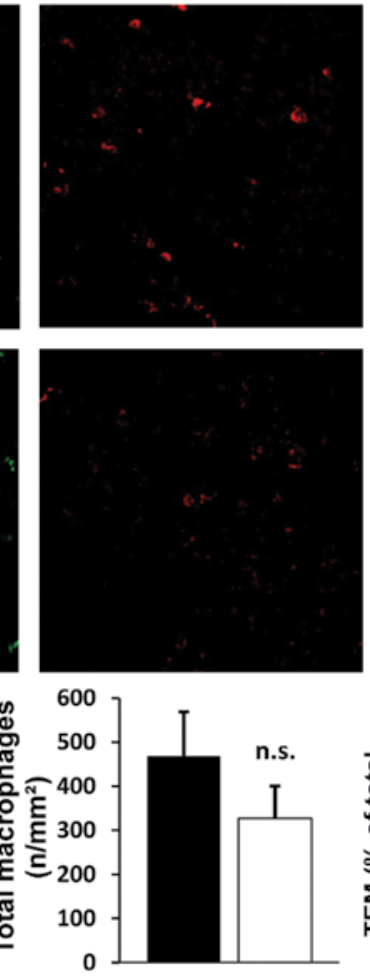

a6fl/fl-Tie2Cre- $\square$ a6fl/fl-Tie2Cre+
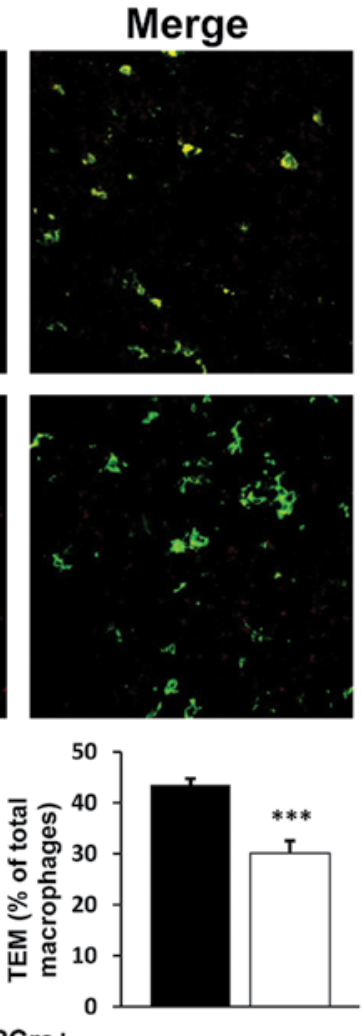

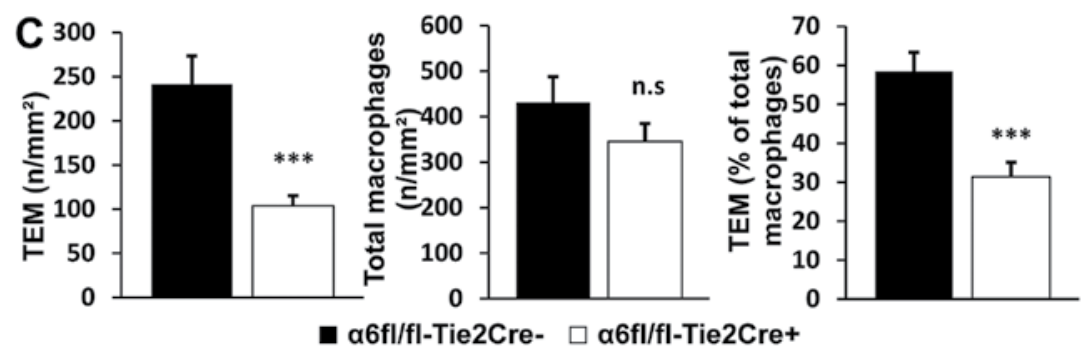

Figure 4. Tie2-dependent $\alpha 6$ deletion reduces infiltration by Tie2-expressing macrophages. Representative photomicrographs (A) and quantitative analysis of TEMs and total macrophages in cryosections of B16F10 tumors from $\alpha 6 \mathrm{fl} / \mathrm{fl}-\mathrm{Tie} 2 \mathrm{Cre}{ }^{-}(\boldsymbol{\square}, \mathrm{n}=7)$ and $\alpha 6 \mathrm{fl} / \mathrm{fl}-\mathrm{Tie} 2 \mathrm{Cre}{ }^{+}(\square, \mathrm{n}=9) \mathrm{mice}, 12 \mathrm{days}$ after tumor implantation (B) or when tumors have identical size in the 2 groups ( $\mathrm{n}=10$ in each group) (C). Sections were stained green with an anti-F4/80 antibody and red with an anti-Tie2 antibody. Scale bar, $100 \mu \mathrm{m}$. Data are means \pm SEM. ${ }^{*} \mathrm{P}<0.05$ and ${ }^{* * *} \mathrm{P}<0.001$.

Tie2-dependent deletion of $\alpha 6$ integrin subunit on peripheral blood monocytes. The proportion of peripheral blood monocytes positive for $\alpha 6$ was $52.5 \pm 7.6 \%$ in $\alpha 6 \mathrm{fl} / \mathrm{fl}-\mathrm{Tie} 2 \mathrm{Cre}^{-}$mice and only $1.85 \pm 0.60 \%$ in $\alpha 6 \mathrm{fl} / \mathrm{fl}-\mathrm{Tie} 2 \mathrm{Cre}^{+}$mice (mean $\pm \mathrm{SEM}$, $\mathrm{n}=5$ mice/genotype, $\mathrm{P}<0.01$ ).

Tie2-dependent deletion of $\alpha 6$ integrin subunit does not significantly change pericyte coverage of tumor blood vessels. The percentage of blood vessels that were positive for $\alpha$ SMA was $38.7 \pm 6.2 \%$ in $\alpha 6 \mathrm{fl} / \mathrm{fl}-\mathrm{Tie} 2 \mathrm{Cre}^{-}$mice $(\mathrm{n}=5)$ and $33.25 \pm 6.5 \%$ in $\alpha 6 \mathrm{fl} / \mathrm{fl}-\mathrm{Tie} 2 \mathrm{Cre}^{+}$mice $(\mathrm{n}=8)($ mean \pm SEM) (Fig. 5A and B). The ratio of $\alpha \mathrm{SMA} / \mathrm{CD} 31$ surface areas was $0.19 \pm 0.03$ in $\alpha 6 \mathrm{fl} / \mathrm{fl}-\mathrm{Tie} 2 \mathrm{Cre}-$ mice $(\mathrm{n}=5)$ and $0.21 \pm 0.03$ in $\alpha 6 \mathrm{fl} / \mathrm{fl}-\mathrm{Tie} 2 \mathrm{Cre}^{+}$ mice $(\mathrm{n}=8)($ mean \pm SEM) (Fig. 5A and C). There was no statistically significant difference between the two genotypes.

\section{Discussion}

Tie2-dependent $\alpha 6$ deletion significantly reduced tumor angiogenesis and, consequently, tumor growth in a B16F10 mouse melanoma model. The number of tumor blood vessels was significantly lower in $\alpha 6 \mathrm{fl} / \mathrm{fl}-\mathrm{Tie} 2 \mathrm{Cre}^{+}$mice than in $\alpha 6 \mathrm{fl} / \mathrm{fl}-\mathrm{Tie} 2 \mathrm{Cre}$ mice. This difference is not due to a difference in tumor size as the analysis of size-matched tumors led to the same conclusion. These latter results are in keeping with those reported by Lee et al (16) and Primo et al (17), who used an anti- $\alpha 6$ blocking antibody (GoH3), and also with our previous results on post-ischemic angiogenesis (19). Indeed, $\alpha 6$ is required for endothelial cell adhesion and migration and for pseudotube formation in vitro $(13,16,18)$. In contrast, however, Germain et al (22) observed enhanced neovessel formation in $\alpha 6 \mathrm{fl} / \mathrm{fl}-\mathrm{Tiel} \mathrm{Cre}^{+}$mice compared to $\alpha 6 \mathrm{ff} / \mathrm{fl}-\mathrm{TielCre}$ mice. The most likely explanation for these conflicting results is VEGFR2 overexpression on endothelial cells from $\alpha 6 \mathrm{fl} / \mathrm{fl}-\mathrm{Tie} 1 \mathrm{Cre}^{+}$mice compared to $\alpha 6 \mathrm{fl} / \mathrm{fl}-\mathrm{Tie} 1 \mathrm{Cre}-\mathrm{mice}^{-}$and the lack of this compensatory mechanism in $\alpha 6 \mathrm{fl} / \mathrm{fl}-\mathrm{Tie} 2 \mathrm{Cre}^{+}$ mice. Indeed, we have shown that the loss of $\alpha 6$ expression on endothelial cells isolated from $\alpha 6 \mathrm{fl} / \mathrm{fl}-\mathrm{Tie} 2 \mathrm{Cre}^{+}$was not counterbalanced by other integrins or VEGFR2 overexpression (19). Another difference between the Tie1Cre and Tie2Cre 

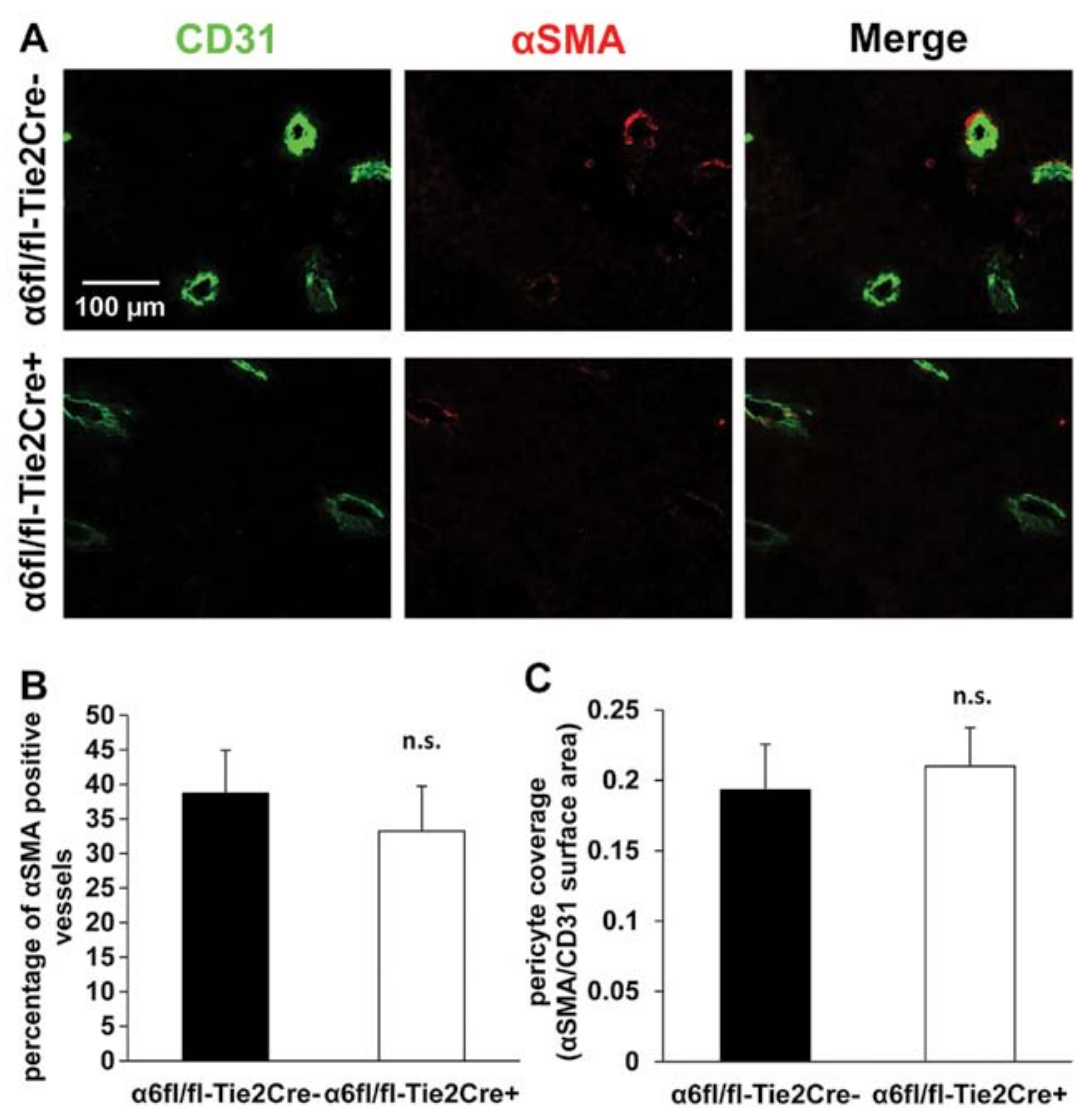

Figure 5. Analysis of pericyte coverage of tumor blood vessels. Representative photomicrographs (A) and quantitative analysis of the percentage of $\alpha$ SMApositive blood vessels (B) and of the ratio of $\alpha \mathrm{SMA} / \mathrm{CD} 31$ surface areas (C) in cryosections of B16F10 tumors from $\alpha 6 \mathrm{fl} / \mathrm{fl}-\mathrm{Tie} 2 \mathrm{Cre}-(\mathbf{\square}, \mathrm{n}=5)$ and $\alpha 6 \mathrm{fl} / \mathrm{fl}-\mathrm{Tie} 2 \mathrm{Cre}{ }^{+}$ $(\square, \mathrm{n}=8)$ mice. Sections were stained green with an anti-CD31 antibody and red with an anti- $\alpha$ SMA antibody. Scale bar, $100 \mu \mathrm{m}$. Data are means \pm SEM.

models is that Tiel is restricted to endothelial cells, whereas Tie2 is expressed on endothelial cells, pericyte precursors of mesenchymal origin, subsets of hematopoietic stem cells, and also a subset of monocytes/macrophages (25). Angiopoietin 2 release by endothelial cells in tumors is upregulated by hypoxia, and its receptor, Tie2, is strongly upregulated when monocytes are recruited into the tumor and differentiate into perivascular macrophages (26). These Tie2-expressing macrophages (TEMs) are highly proangiogenic: they secrete growth factors such as VEGF and matrix metalloproteinases such as MMP9 and thereby promote neovessel formation in endometriotic lesions and tumors (26-28). TEM targeting might thus enhance anti-angiogenic therapy efficiency (29-31). About $50 \%$ of peripheral blood monocytes were positive for $\alpha 6$ in our $\alpha 6 f 1 / f l-T i e 2 \mathrm{Cre}^{-}$mice, whereas nearly all were negative for $\alpha 6$ in $\alpha 6 f l / f l-T i e 2 \mathrm{Cre}^{+}$mice, suggesting that Tie2-dependent $\alpha 6$ deletion also occurred efficiently in monocytes. Consequently, $\alpha 6$ would also be deleted from TEMs in $\alpha 6 \mathrm{fl} / \mathrm{fl}-\mathrm{Tie} 2 \mathrm{Cre}^{+}$mice, and we found that TEM tumor infiltration was significantly reduced compared to $\alpha 6 \mathrm{fl} / \mathrm{fl}-\mathrm{Tie} 2 \mathrm{Cre}^{-}$mice. In macrophages, $\alpha 6$ ligation on laminin triggers intracellular phosphorylation and cytoskeleton rearrangement (6). This would explain why $\alpha 6$ deletion in TEMs inhibits their infiltration, as TEM tumor infiltration involves laminin interaction and transendothelial migration steps. Administration of $\alpha 6$ blocking antibodies might also reduce TEM infiltration, a possibility not investigated by Lee et al (16) and Primo et al (17).
Interestingly, we also found fewer microvessels in tumors from $\alpha 6$ fl/fl-Tie $2 \mathrm{Cre}^{+}$mice, resulting in a slightly increased average vessel diameter. This could stem from a decreased sprouting capacity, as we have previously found that neovessel outgrowth from preexisting blood vessels in the ex vivo aortic ring assay is reduced in $\alpha 6 f l / f l-T i e 2 \mathrm{Cre}^{+}$mice (19). In addition, it has been demonstrated using a three dimensional in vitro co-culture model, that $\alpha 6$ expression increases on both endothelial cells and pericytes when they are cultured together, and that the addition of an anti- $\alpha 6$ blocking antibody leads to an increased vessel width in pericyte-endothelial cell cocultures but not in endothelial cell monocultures (32). This suggests that $\alpha 6$ could play a role in pericyte-endothelial cell interactions and therefore in vessel morphogenesis and maturation. However, we did not find any significant genotype-dependent difference in the pericyte coverage of the blood vessels of B16F10 tumors from $\alpha 6 \mathrm{fl} / \mathrm{fl}-\mathrm{Tie} 2 \mathrm{Cre}^{+}$mice compared to $\alpha 6 f l / f l-T i e 2 C^{-}$mice, suggesting that pericyte recruitment is not impaired in this model.

Endothelial progenitor cells (EPCs) can also participate in tumor angiogenesis (33). We have previously shown that $\alpha 6$ is involved in EPC mobilization from bone marrow after ischemia (19). We used flow cytometry to determine the number of circulating EPCs in the peripheral blood of tumorbearing mice, as previously described (19), and found no genotype-dependent difference (data not shown). However, it is possible that EPC recruitment to tumors may be reduced in 
$\alpha 6 \mathrm{fl} / \mathrm{fl}-\mathrm{Tie} 2 \mathrm{Cre}^{+}$mice compared to $\alpha 6 \mathrm{fl} / \mathrm{fl}-\mathrm{Tie} 2 \mathrm{Cre}-$, as we have previously shown that $\alpha 6$ is required for EPC recruitment to ischemic tissues (18).

This study highlights differences between Tie1Cre and Tie2Cre conditional knockout models. Our results confirm that $\alpha 6$ plays an important role in tumor growth and angiogenesis, by promoting neovessel formation and tumor infiltration by proangiogenic TEMs. Therapeutic targeting of $\alpha 6$ might affect the invasive properties of tumor cells, endothelial cells and TEMs, and could thereby reduce tumor growth and invasiveness.

\section{Acknowledgements}

This study would not have been possible without the contribution of E.G.-L. who provided $\alpha 6$-floxed mice. Sadly, E.G.-L. passed away prematurely on July 21,2012. We thank Mevyn Nizard and Eric Tartour for the generous gift of the B16F10 melanoma cell line and Lydia Sorokin for the antibodies against laminin $\alpha 4$ and $\alpha 5$ chains. We thank the staff of the Institut Médicament, Toxicologie, Chimie, Environnement animal facility and imaging platform for their help and advice. Claire Bouvard was supported by grants from Ministère de l'Enseignement Supérieur et de la Recherche and the French Society of Haematology.

\section{References}

1. Avraamides CJ, Garmy-Susini B and Varner JA: Integrins in angiogenesis and lymphangiogenesis. Nat Rev Cancer 8: 604-617, 2008.

2. Garmy-Susini B and Varner JA: Roles of integrins in tumor angiogenesis and lymphangiogenesis. Lymphat Res Biol 6: $155-163,2008$

3. Hogervorst F, Admiraal LG, Niessen C, et al: Biochemical characterization and tissue distribution of the $\mathrm{A}$ and $\mathrm{B}$ variants of the integrin alpha 6 subunit. J Cell Biol 121: 179-191, 1993.

4. Terpe HJ, Stark H, Ruiz P and Imhof BA: Alpha 6 integrin distribution in human embryonic and adult tissues. Histochemistry 101: 41-49, 1994.

5. Sonnenberg A, Linders CJ, Daams JH and Kennel SJ: The alpha 6 beta 1 (VLA-6) and alpha 6 beta 4 protein complexes: tissue distribution and biochemical properties. J Cell Sci 96: 207-217, 1990.

6. Shaw LM, Messier JM and Mercurio AM: The activation dependent adhesion of macrophages to laminin involves cytoskeletal anchoring and phosphorylation of the alpha 6 beta 1 integrin. J Cell Biol 110: 2167-2174, 1990.

7. Hallmann R, Horn N, Selg M, Wendler O, Pausch F and Sorokin LM: Expression and function of laminins in the embryonic and mature vasculature. Physiol Rev 85: 979-1000, 2005.

8. Chung J and Mercurio AM: Contributions of the alpha6 integrins to breast carcinoma survival and progression. Mol Cells 17: 203-209, 2004

9. Zhu GH, Huang C, Qiu ZJ, et al: Expression and prognostic significance of CD151, c-Met, and integrin alpha3/alpha6 in pancreatic ductal adenocarcinoma. Dig Dis Sci 56: 1090-1098, 2011.

10. Rabinovitz I, Nagle RB and Cress AE: Integrin alpha 6 expression in human prostate carcinoma cells is associated with a migratory and invasive phenotype in vitro and in vivo. Clin Exp Metastasis 13: 481-491, 1995

11. Delamarre E, Taboubi S, Mathieu S, et al: Expression of integrin alpha6beta1 enhances tumorigenesis in glioma cells. Am J Pathol 175: 844-855, 2009.

12. Colomiere M, Findlay J, Ackland L and Ahmed N: Epidermal growth factor-induced ovarian carcinoma cell migration is associated with JAK2/STAT3 signals and changes in the abundance and localization of $\alpha 6 \beta 1$ integrin. Int J Biochem Cell Biol 41 : 1034-1045, 2009.
13. Chabut D, Fischer AM, Colliec-Jouault S, et al: Low molecular weight fucoidan and heparin enhance the basic fibroblast growth factor-induced tube formation of endothelial cells through heparan sulfate-dependent alpha6 overexpression. Mol Pharmacol 64: 696-702, 2003.

14. Zemani F, Benisvy D, Galy-Fauroux I, et al: Low-molecular-weight fucoidan enhances the proangiogenic phenotype of endothelial progenitor cells. Biochem Pharmacol 70: 1167-1175, 2005.

15. Smadja DM, Bieche I, Helley D, et al: Increased VEGFR2 expression during human late endothelial progenitor cells expansion enhances in vitro angiogenesis with up-regulation of integrin alpha(6). J Cell Mol Med 11: 1149-1161, 2007.

16. Lee TH, Seng S, Li H, Kennel SJ, Avraham HK and Avraham S: Integrin regulation by vascular endothelial growth factor in human brain microvascular endothelial cells: role of alpha6beta1 integrin in angiogenesis. J Biol Chem 281: 40450-40460, 2006.

17. Primo L, Seano G, Roca C, et al: Increased expression of alpha6 integrin in endothelial cells unveils a proangiogenic role for basement membrane. Cancer Res 70: 5759-5769, 2010.

18. Bouvard C, Gafsou B, Dizier B, et al: Alpha6-integrin subunit plays a major role in the proangiogenic properties of endothelial progenitor cells. Arterioscler Thromb Vasc Biol 30: 1569-1575, 2010.

19. Bouvard C, De Arcangelis A, Dizier B, et al: Tie2-dependent knockout of $\alpha 6$ integrin subunit in mice reduces post-ischaemic angiogenesis. Cardiovasc Res 95: 39-47, 2012.

20. Ljubimova JY, Fujita M, Khazenzon NM, Ljubimov AV and Black KL: Changes in laminin isoforms associated with brain tumor invasion and angiogenesis. Front Biosci 11: 81-88, 2006.

21. Fujita M, Khazenzon NM, Bose S, et al: Overexpression of beta1chain-containing laminins in capillary basement membranes of human breast cancer and its metastases. Breast Cancer Res 7: R411-R421, 2005.

22. Germain M, De Arcangelis A, Robinson SD, et al: Genetic ablation of the alpha 6-integrin subunit in Tie1Cre mice enhances tumour angiogenesis. J Pathol 220: 370-381, 2010.

23. Ringelmann B, Roder C, Hallmann R, et al: Expression of laminin alpha1, alpha2, alpha4, and alpha5 chains, fibronectin, and tenascin-C in skeletal muscle of dystrophic $129 \mathrm{ReJ} \mathrm{dy} / \mathrm{dy}$ mice. Exp Cell Res 246: 165-182, 1999.

24. Sorokin LM, Pausch F, Frieser M, Kroger S, Ohage E and Deutzmann R: Developmental regulation of the laminin alpha5 chain suggests a role in epithelial and endothelial cell maturation. Dev Biol 189: 285-300, 1997.

25. De Palma M, Venneri MA, Galli R, et al: Tie2 identifies a hematopoietic lineage of proangiogenic monocytes required for tumor vessel formation and a mesenchymal population of pericyte progenitors. Cancer Cell 8: 211-226, 2005.

26. Coffelt SB, Tal AO, Scholz A, et al: Angiopoietin-2 regulates gene expression in TIE2-expressing monocytes and augments their inherent proangiogenic functions. Cancer Res 70: 5270-5280, 2010.

27. Capobianco A, Monno A, Cottone L, et al: Proangiogenic Tie(2) macrophages infiltrate human and murine endometriotic lesions and dictate their growth in a mouse model of the disease. Am J Pathol 179: 2651-2659, 2011.

28. Mazzieri R, Pucci F, Moi D, et al: Targeting the ANG2/TIE2 axis inhibits tumor growth and metastasis by impairing angiogenesis and disabling rebounds of proangiogenic myeloid cells. Cancer Cell 19: 512-526, 2011.

29. Squadrito ML and De Palma M: Macrophage regulation of tumor angiogenesis: implications for cancer therapy. Mol Aspects Med 32: 123-145, 2011.

30. Welford AF, Biziato D, Coffelt SB, et al: TIE2-expressing macrophages limit the therapeutic efficacy of the vascular-disrupting agent combretastatin A4 phosphate in mice. J Clin Invest 121: 1969-1973, 2011.

31. Huang H, Lai JY, Do J, et al: Specifically targeting angiopoietin-2 inhibits angiogenesis, Tie2-expressing monocyte infiltration, and tumor growth. Clin Cancer Res 17: 1001-1011, 2011.

32. Stratman AN, Malotte KM, Mahan RD, Davis MJ and Davis GE: Pericyte recruitment during vasculogenic tube assembly stimulates endothelial basement membrane matrix formation. Blood 114: 5091-5101, 2009.

33. Nolan DJ, Ciarrocchi A, Mellick AS, et al: Bone marrow-derived endothelial progenitor cells are a major determinant of nascent tumor neovascularization. Genes Dev 21: 1546-1558, 2007. 